Supporting Information

\title{
Formation of Stable Metal Halide Perovskite/Perovskite Heterojunctions
}

Catherine P. Clark, ${ }^{a}$ Jennifer E. Mann, ${ }^{b}$ John S. Bangsund, ${ }^{a}$ Wan-Ju Hsu, ${ }^{a}$ Eray S. Aydil, ${ }^{c}$ and

Russell J. Holmes*a

${ }^{a}$ Department of Chemical Engineering and Materials Science, University of Minnesota, Minneapolis, MN 55455, USA.

b Physical Electronics, Inc., 18725 Lake Dr E, Chanhassen, MN 55317, USA.

${ }^{c}$ Department of Chemical and Biomolecular Engineering, Tandon School of Engineering, New York University, Brooklyn, NY, 11201, USA.

\section{Corresponding Author}

*Email: rholmes@umn.edu 


\section{Perovskite Film Synthesis}

Glass and/or Si substrates were cleaned via sequential sonication in baths of diluted tergitol, deionized water, and acetone. Substrates were then boiled in isopropanol, dried with $\mathrm{N}_{2}$, and treated with UV-ozone for 15 minutes.

All materials were used as received: $\mathrm{PbBr}_{2}$ (Sigma Aldrich, 99.999\% metals basis), $\mathrm{PbI}_{2}$ (Sigma Aldrich, 99.999\% metals basis), MABr (Sigma Aldrich, >99\% purity), FABr (Sigma Aldrich, 98\% purity), FAI (Sigma Aldrich, >99\% purity), $\mathrm{SnBr}_{2}$ (BTC, 99\% purity), MAI (Lumtec, 99.5\% purity), $\mathrm{SnI}_{2}$ (Alfa Aesar, 99.999\% purity), CsBr (Sigma Aldrich, 99.9\% trace metals basis), $N, N$-Dimethylformamide (anhydrous, 99.8\%), Chlorobenzene (anhydrous, 99.8\%), Dimethyl sulfoxide (anhydrous, $\geq 99.9 \%$ ), where $\mathrm{MA}=\mathrm{CH}_{3} \mathrm{NH}_{3}$ and $\mathrm{FA}=\mathrm{CH}\left(\mathrm{NH}_{2}\right)_{2}$.

$\mathbf{M A P b B r}_{3} \& \mathbf{F A P b B r}_{3}: \mathrm{MAPbBr}_{3} \& \mathrm{FAPbBr}_{3}$ films were synthesized using a 1-step spin coating process inside of an $\mathrm{N}_{2}$ glovebox. $1 \mathrm{M}$ or $0.6 \mathrm{M} \mathrm{MAPbBr} 3$ solutions (depending on desired film thickness) with $15 \%$ excess $\mathrm{MABr}$ were made by dissolving 1:1.15 molar ratios of $\mathrm{PbBr}_{2}: \mathrm{MABr}$ in a 4:1 volume ratio of DMF:DMSO. $0.6 \mathrm{M} \mathrm{FAPbBr} 3$ solutions were made by dissolving 1:1.10 molar ratio of $\mathrm{PbBr}_{2}: \mathrm{FABr}$ in a 4:1 volume ratio of DMF:DMSO. Solutions were stirred at $1000 \mathrm{rpm}$ until dissolved and filtered with a $0.2 \mu \mathrm{m}$ PTFE filter. Films were then static spin coated at $3000 \mathrm{rpm}$ for 2 minutes, with $200 \mu \mathrm{L}$ of chlorobenzene dropped between $10 \mathrm{~s}$ and 45 s into the spin cycle. Films were then annealed at $95{ }^{\circ} \mathrm{C}$ for 60 minutes. Small-grained films were fabricated with chlorobenzene drip at $10 \mathrm{~s}$ or $15 \mathrm{~s}$, whereas large island morphologies were fabricated with chlorobenzene drip at $>25 \mathrm{~s}$.

$\mathrm{CsPbBr}_{3}: \mathrm{CsPbBr}_{3}$ films were synthesized using a 1-step spin coating process inside an $\mathrm{N}_{2}$ glovebox following Cho et al. ${ }^{1} \mathrm{~A} 10.4 \mathrm{wt} \% \mathrm{CsPbBr}_{3}$ with $10 \%$ molar excess $\mathrm{CsBr}$ solution was made by dissolving $\mathrm{PbBr}_{2}$ and $\mathrm{CsBr}$ in DMSO. Solutions were stirred at $60{ }^{\circ} \mathrm{C}$ and $1000 \mathrm{rpm}$ until dissolved and filtered with a $0.2 \mu \mathrm{m}$ PTFE filter. Films were then static spin coated at $3000 \mathrm{rpm}$ 
for 2 minutes and then annealed at $95{ }^{\circ} \mathrm{C}$ for 60 minutes. While annealing $\mathrm{CsPbBr}_{3}$ at $250-350$ ${ }^{\circ} \mathrm{C}$ may be common, these high temperatures are neither desired nor necessary for making efficient devices especially on flexible substrates. Indeed, there are already many reports like that of Cho et al. who has achieved bright and efficient light-emitting $\mathrm{CsPbBr}_{3}$ devices via annealing at 70 ${ }^{\circ} \mathrm{C} .{ }^{1}$ Thus, lower than usual annealing temperatures $\left(95^{\circ} \mathrm{C}\right)$ were chosen. Because small grains enhance diffusion and mixing (see main text), annealing the bottom layer at lower temperatures is a more stringent test of the stability of the heterojunctions. The stability of the heterojunctions when $\mathrm{CsPbBr}_{3}$ is annealed at higher temperatures is expected to be better since the grains will be larger.

MAPbI3: $\mathrm{MAPbI}_{3}$ films were synthesized using a 1-step spin coating process inside an $\mathrm{N}_{2}$ glovebox. $0.3 \mathrm{M} \mathrm{MAPbI}_{3}$ solutions were made by dissolving 1:1.10 molar ratios of $\mathrm{PbI}_{2}: \mathrm{MAI}$ in a 4:1 volume ratio of DMF:DMSO. Solutions were stirred at $1000 \mathrm{rpm}$ until dissolved and filtered with a $0.2 \mu \mathrm{m}$ PTFE filter. Films were then static spin coated at $3000 \mathrm{rpm}$ for 2 minutes and then annealed at $95^{\circ} \mathrm{C}$ for 60 minutes.

FAPbI 3 : $\mathrm{FAPbI}_{3}$ films were synthesized using a 2-step process inside an $\mathrm{N}_{2}$ glovebox following Binek et al. ${ }^{2} \mathrm{~A} 1 \mathrm{M} \mathrm{PbI}_{2}$ solution was made my dissolving $\mathrm{PbI}_{2}$ in $\mathrm{DMF}$, stirring at 1000 rpm and heating at $60{ }^{\circ} \mathrm{C}$ until dissolved. The $\mathrm{PbI}_{2}$ solution was then filtered with a $0.2 \mu \mathrm{m}$ PTFE filter. A $20 \mathrm{mM}$ of organic halide solution was then made with 85\% FAI and 15\% MAI in IPA and stirred at $1000 \mathrm{rpm}$ until dissolved. Both solutions were kept at $60{ }^{\circ} \mathrm{C}$ during film synthesis. First, a $\mathrm{PbI}_{2}$ film was deposited via dynamic spin coating $80 \mu \mathrm{L}$ PbI2 solution at $3000 \mathrm{rpm}$ for 15 seconds. Immediately after spin coating, the films were gently immersed in the FAI/MAI/IPA solution for 4-5 minutes, at which point they were spin coated at $3000 \mathrm{rpm}$ for $5 \mathrm{~s}$ to remove remaining solution. 
$\operatorname{MASnBr}_{3}$ \& MASnI $\mathbf{M A S n B r}_{3}$ and $\mathrm{MASnI}_{3}$ films were fabricated using a carrier-gas assisted vapor deposition technique described in detail in our previous work. ${ }^{3}$ To prepare for deposition, the inside of the deposition chamber and source ampoules were wiped with acetone and isopropanol, and then baked at $350{ }^{\circ} \mathrm{C}$ and pressures $<20 \mathrm{mTorr}$ for at least 1 hour. The furnace temperature is then set to $280{ }^{\circ} \mathrm{C}$ and allowed to equilibrate prior to deposition.

For each source material, $\sim 100 \mathrm{mg}$ of powder $\left(\mathrm{MAI}\right.$ and $\mathrm{SnI}_{2}$ for $\mathrm{MASnI}_{3}, \mathrm{MABr}$ and $\mathrm{SnBr}_{2}$ for $\mathrm{MASnBr}_{3}$ ) was packed tightly into a quartz sample holder and inserted into the deposition chamber using a linear feedthrough. Following, the solution-processed $\mathrm{APbX}_{3}$ films were attached to a copper substrate holder with a thermally conductive silicone pad (Wathai $0.5 \mathrm{~mm}$ thick, $2.0 \mathrm{~W} / \mathrm{mK}$ ).

The chamber was evacuated and held at a pressure of $<20$ mTorr for 5 minutes. The substrate cooling water circulator was turned on, and the desired substrate temperature was achieved by manipulating the flow control valve and/or the recirculating water temperature.

The source materials were then positioned at distances corresponding to the desired temperature. The source temperatures were monitored in situ with thermocouples and the axial position of the sources were adjusted until the desired temperature was reached and remained stable (typically takes $\sim 10$ minutes). Deposition began when the $\mathrm{N}_{2}$ carrier gases for each source material were set to the desired rate using mass flow controllers and ended when the source materials were pulled back into the cold portion of the $\mathrm{N}_{2}$ manifold and the carrier gas was simultaneously turned off. Films were stored in the dark in a $\mathrm{N}_{2}$ glovebox at room temperature except for when they were being characterized.

The deposition parameters for $\mathrm{MASnBr}_{3} \& \mathrm{MASnI}_{3}$ films reported herein are shown in Table S1. 
Table S1. Carrier-gas assisted vapor deposition parameters for $\mathrm{MASnBr}_{3} \& \mathrm{MASnI}_{3} \mathrm{films}$

\begin{tabular}{|c|c|c|c|c|}
\hline & \multicolumn{2}{|c|}{$\mathrm{MASnBr}_{3}$} & \multicolumn{2}{|c|}{$\mathrm{MASnI}_{3}$} \\
\hline & MABr & $\mathrm{SnBr}_{2}$ & MAI & $\mathrm{SnI}_{2}$ \\
\hline Carrier gas flow rate & \multicolumn{2}{|c|}{$3 \mathrm{sccm}$} & \multicolumn{2}{|c|}{$3-4 \mathrm{sccm}$} \\
\hline Dilution gas flow rate & \multicolumn{4}{|c|}{$\sim 50 \mathrm{sccm}$} \\
\hline Source temperature & $140-145^{\circ} \mathrm{C}$ & $230-235^{\circ} \mathrm{C}$ & $140-150^{\circ} \mathrm{C}$ & $260-270{ }^{\circ} \mathrm{C}$ \\
\hline Substrate temperature & \multicolumn{4}{|c|}{$10-15^{\circ} \mathrm{C}$} \\
\hline Chamber Temperature & \multicolumn{4}{|c|}{$280^{\circ} \mathrm{C}$} \\
\hline Chamber Pressure & \multicolumn{2}{|c|}{ 0.5 Torr } & \multicolumn{2}{|c|}{$0.5-0.6$ Torr } \\
\hline
\end{tabular}

\section{Film Characterization}

Film thicknesses were measured using a J.A. Wollam Spectroscopic Ellipsometer and Cauchy model fit. Absorbance measurements were performed with a CARY 7000 UV-VIS-IR spectrometer. X-ray diffraction was collected using a PANalytical X'pert PRO diffractometer (Co K $\alpha$ radiation, $\lambda=1.7889 \AA$ ). Scanning Electron Microscope (SEM) images were obtained using a JEOL 6500 instrument with $5 \mathrm{kV}$ potential and $30 \mathrm{~mA}$ current. For heterojunctions where both absorption and XRD data are presented, the data were taken on the same sample. For example, data in Figure 2d and 2e are from the same heterojunction film.

XPS measurements were performed using a Physical Electronics VersaProbe III Scanning XPS Microprobe using monochromatic $\mathrm{Al} \mathrm{K \alpha}(1486.6 \mathrm{eV}) \mathrm{X}$-rays and $\mathrm{C}_{60}{ }^{+}$sputtering source for depth profiling. Samples were mounted on a sample carrier with non-conductive double-sided adhesive tape. Dual beam charge neutralization, consisting of a beam of low energy $(\sim 1 \mathrm{eV})$ electrons and low energy $(\sim 8 \mathrm{eV}) \mathrm{Ar}^{+}$ions was used during all data acquisitions. The photoelectron take-off angle was 45 degrees for all measurements. To ensure that XPS measurements capture the behavior of the heterojunction across multiple grains and grain boundaries, we used a circular, 100 $\mu \mathrm{m}$ diameter, $25 \mathrm{~W}$ X-ray spot for the data in Figure 1 and a $100 \mu \mathrm{m}$ diameter, $100 \mathrm{~W}$ X-ray source rastered quickly over a $1400 \mu \mathrm{m} \times 100 \mu \mathrm{m}$ area for the data in Figure 3 . These X-ray sizes are 
significantly larger than a typical grain size $\left(<30 \mu \mathrm{m}^{2}\right)$. During sputtering, a $20 \mathrm{kV} / 20 \mathrm{nA} \mathrm{C}_{60}{ }^{+}$ion beam was rastered over a $4 \mathrm{~mm} \times 4 \mathrm{~mm}$ area. Compucentric Zalar ${ }^{\mathrm{TM}}$ Rotation of the sample was used to mitigate non-uniformity in sputtering for the data in Figure 3. The data acquisition times and sputter intervals, as well as the pass energies used, varied depending on the sample. All data were processed using Physical Electronics' MultiPak data reduction software (version 9.9.1.1). The binding energy scale of all spectra was charge corrected by taking the location of the adventitious carbon $\mathrm{C} 1 \mathrm{~s}$ peak observed in the first cycle (before any sputtering has occurred) and shifting it to $284.8 \mathrm{eV}$. In both the mixed and unmixed samples in Figure 3 at least three chemical states of carbon were observed at some point during the depth profile, attributed to atmospheric hydrocarbon contamination (C-C), $\mathrm{MA}^{+}$, and $\mathrm{FA}^{+}$. Curve fitting was performed with MultiPak to separate the three components. In the case of nitrogen, linear least squares (LLS) fitting was used on a cycle where a single chemical state for both $\mathrm{MA}^{+}$and $\mathrm{FA}^{+}$was present for the unmixed depth profile. The spectra used in the unmixed sample for LLS were then used as the basis for the LLS fit of the mixed sample.

The XPS features corresponding to $\mathrm{Sn}$ in perovskites like $\mathrm{MASnBr}_{3}$ generally show two sets of features, one set corresponding to $\mathrm{Sn}^{2+}$ and the other reflecting sputtering damage that is likely elemental Sn. A representative Sn XPS spectrum is shown in Fig. S1 for MASnBr 3 . The red curve is collected prior to depth profiling while the blue curve is taken after some depth profiling. The two prominent peaks in the red curve are consistent with the position of the Sn3d3/2 and $\mathrm{Sn} 3 \mathrm{~d} 5 / 2$ peaks for the $\mathrm{Sn}^{2+}$ oxidation state. If it were present, the 4+ state would appear as a high energy shoulder on each peak, as reported in previous studies of $\mathrm{CsSnI}_{3}{ }^{4}$ Since no such shoulder is observed, there is no evidence of the $\mathrm{Sn}^{4+}$ state. After depth profiling (blue curve), a 
small should appears at lower energy on each peak. Since we do not expect ion induced damage to increase the oxidization state, it is likely that this reflects the formation of elemental $\mathrm{Sn}$.

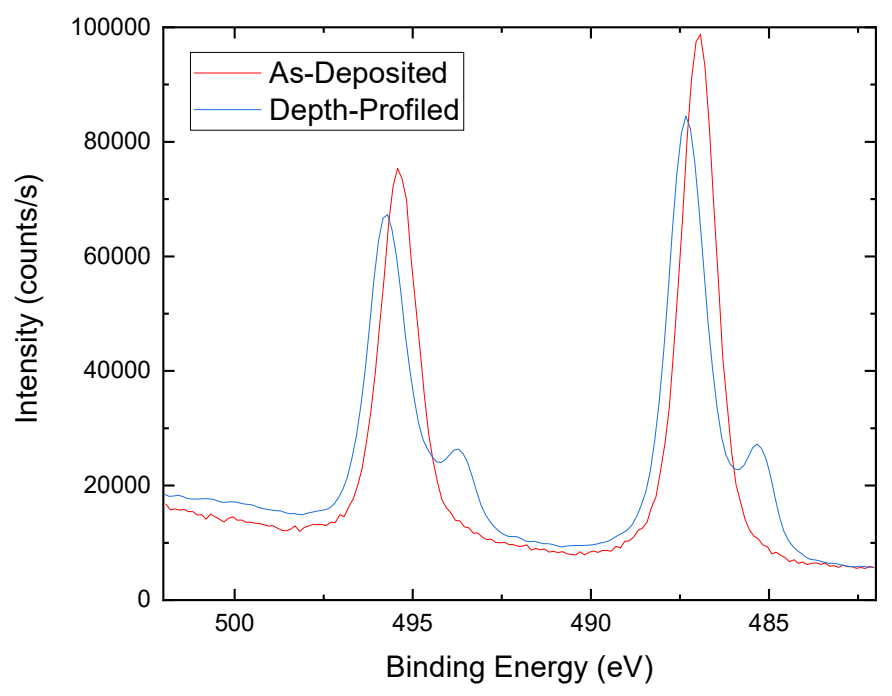

Figure S1. X-ray photoelectron spectra showing the response from Sn in $\mathrm{MASnBr}_{3}$ both before and after depth-profiling. 

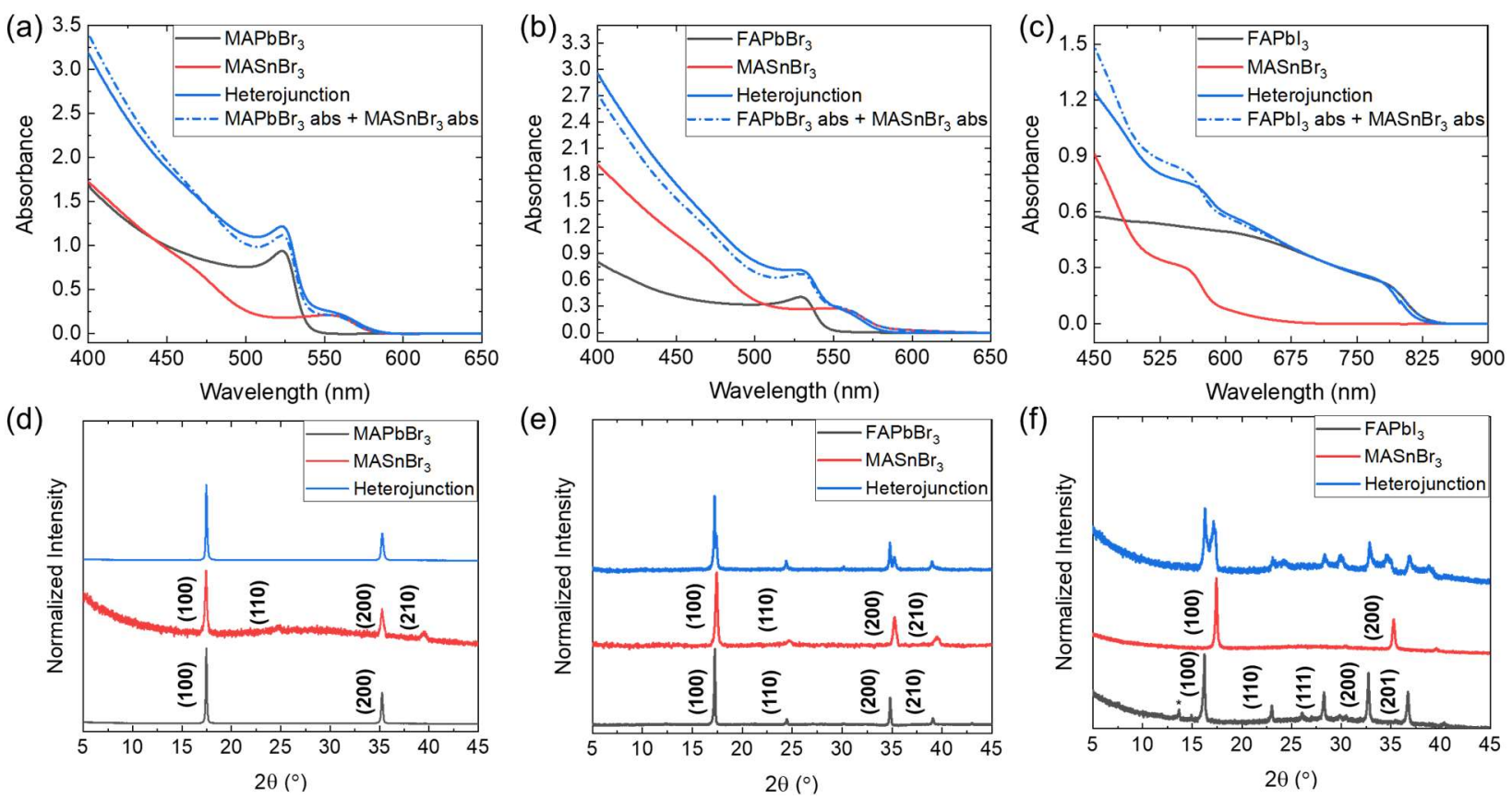

Figure S2 . Absorption data (a) - (c) for individual films and heterojunctions depicted in Figure 1a

- 1c (backgrounds subtracted for clarity). The linear superposition of the individual perovskite films (dashed blue line) aligns well with the measured absorption spectra of the corresponding heterojunction as one would expect for a multi-layer film where the layers are segregated. XRD patterns (d) - (f) corresponding to films in Figure 1d - 1f. The asterisk in (f) corresponds to excess $\mathrm{PbI}_{2}$ phase. XRD was collected using $\mathrm{Co} \mathrm{K} \alpha$ radiation and spectra are normalized to maximum and offset for clarity. 


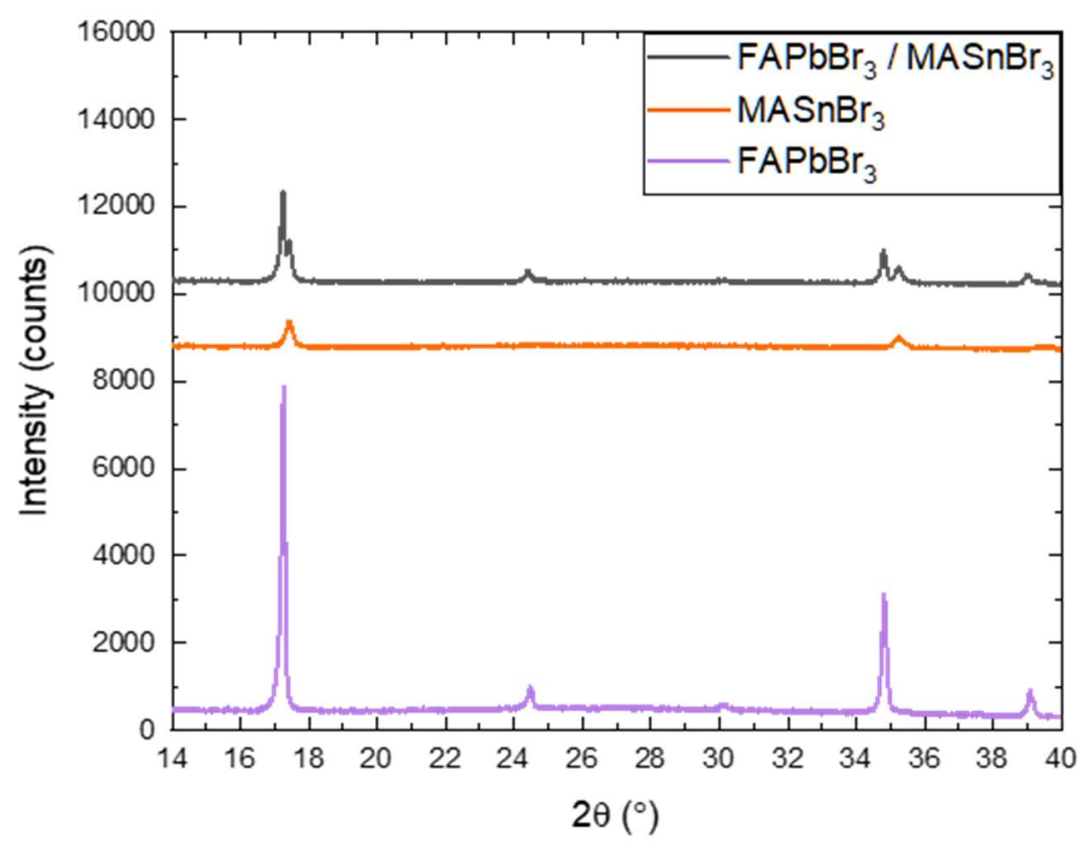

Figure S3: Absolute intensity XRD patterns for the $\mathrm{FAPbBr}_{3} / \mathrm{MASnBr}_{3}$ heterojunction shown in Figure 1e. The intensity of the bottom $\mathrm{FAPbBr}_{3}$ peaks are smaller in the heterojunction pattern (black trace) than in the neat film (purple trace) due to attenuation from the top $\mathrm{MASnBr}_{3}$ layer. 


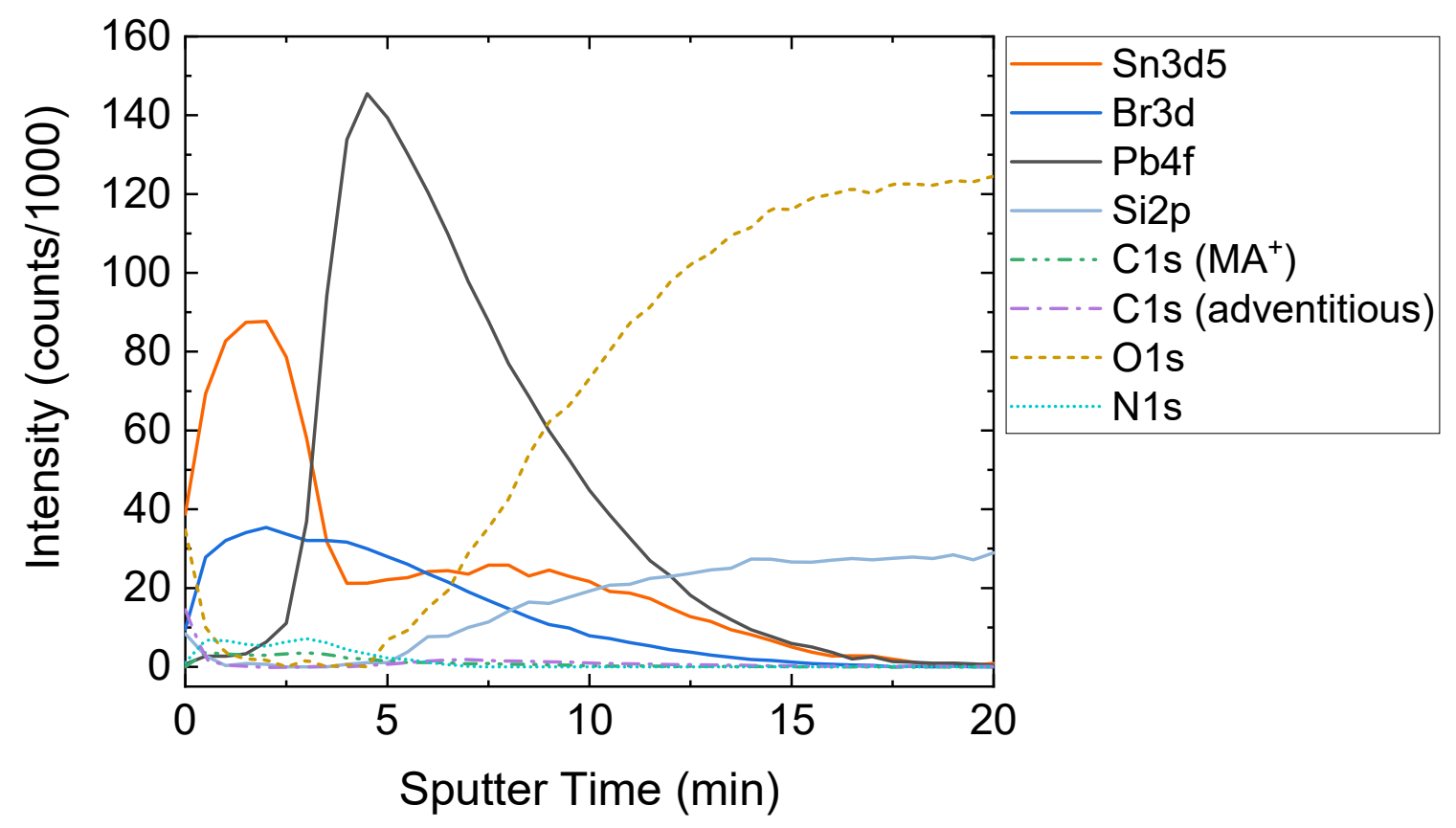

Figure S4. XPS depth profile data for all XPS peaks detected in Figure 1d. 

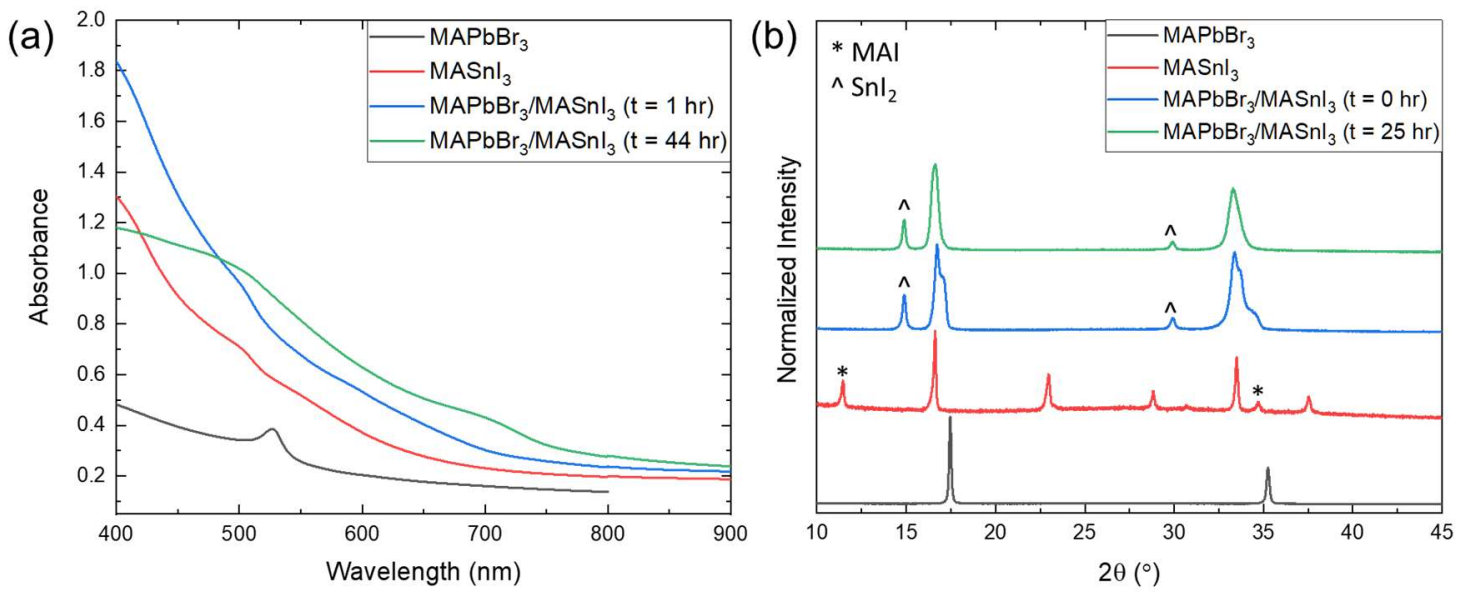

Figure S5. Representative absorbance spectra (a) and XRD patterns (b) of a $\mathrm{MAPbBr}_{3} / \mathrm{MASnI}_{3}$ heterojunction. All samples measured showed substantial mixing for the initial measurements, indicated by the lack of absorption onsets and XRD peaks corresponding to the individual film layers. Whereas substantial MAI excess was observable in the neat $\mathrm{MASnI}_{3}$ film (*) via XRD, the heterojunction had substantial $\mathrm{SnI}_{2}$ excess $\left({ }^{\wedge}\right)$. It is possible that these non-stoichiometries could have contributed to faster mixing via altering the defect distribution. XRD was collected using Co $\mathrm{K} \alpha$ radiation and spectra are normalized to maximum and offset for clarity. 

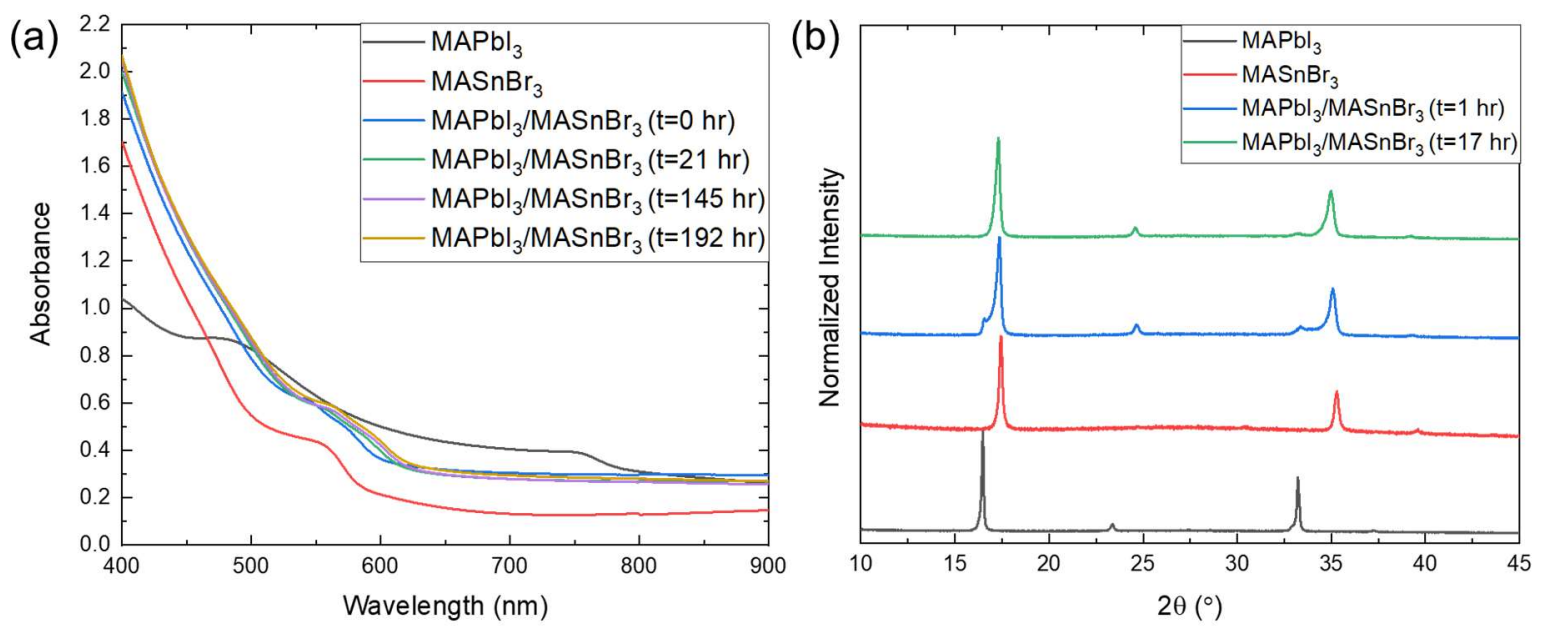

Figure S6. Representative absorbance spectra (a) and XRD patterns (b) of a $\mathrm{MAPbI}_{3} / \mathrm{MASnBr}_{3}$ heterojunction. While initial absorption $(\mathrm{t}=0 \mathrm{hr})$ measurements show evidence for substantial mixing and lack onsets and features at wavelengths corresponding to constituent films $(\lambda \sim 785$ $\mathrm{nm}$ for $\mathrm{MAPbI}_{3}$ and $\lambda \sim 580 \mathrm{~nm}$ for $\mathrm{MASnBr}_{3}$ ), there is a small peak visible in the $\mathrm{t}=1 \mathrm{hr} \mathrm{XRD}$ measurements that corresponds to the $\mathrm{MAPbI}_{3}(100)$ peak at $2 \theta=16.5^{\circ}$; i.e., at 1 hour there is mixing but it is not complete. Measurements at later times for XRD indicate only one phase is present. XRD was collected using Co $\mathrm{K} \alpha$ radiation and spectra are normalized to maximum and offset for clarity. 

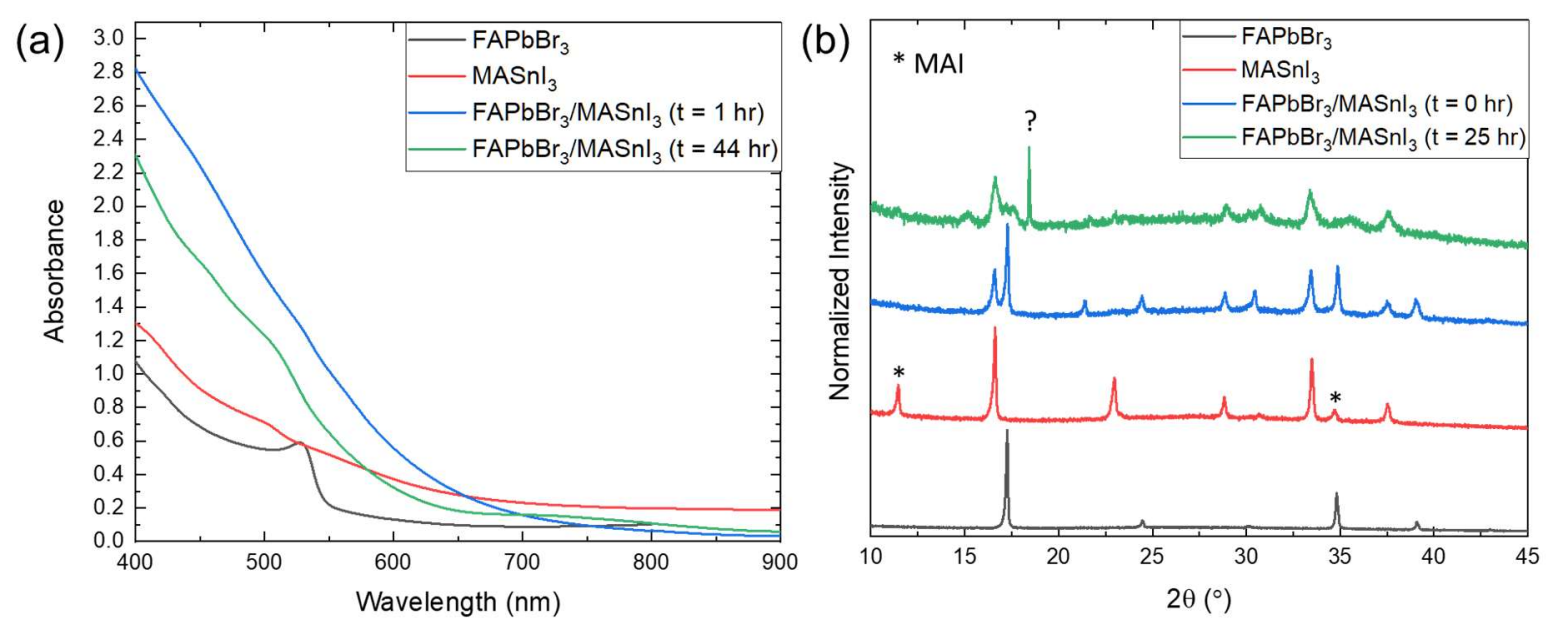

Figure S7. Representative absorbance spectra (a) and XRD patterns (b) of a $\mathrm{FAPbBr} 3 \mathrm{MASnI}_{3}$ heterojunction, where $\mathrm{t}=0 \mathrm{hr}$ XRD measurements shows peaks corresponding to both constituent layers. MAI (*) is visible in the neat $\mathrm{MASnI}_{3}$ film but not in the heterojunction, it is possible that these non-stoichiometries could have contributed to faster mixing via altering the defect distribution. XRD spectra at $\mathrm{t}=25 \mathrm{hr}$ shows substantial mixing alongside potential degradation, as sharp peak at $2 \theta=16.5^{\circ}$ does not correspond to either constituent MHP. XRD was collected using Co K $\alpha$ radiation and spectra are normalized to maximum and offset for clarity. 

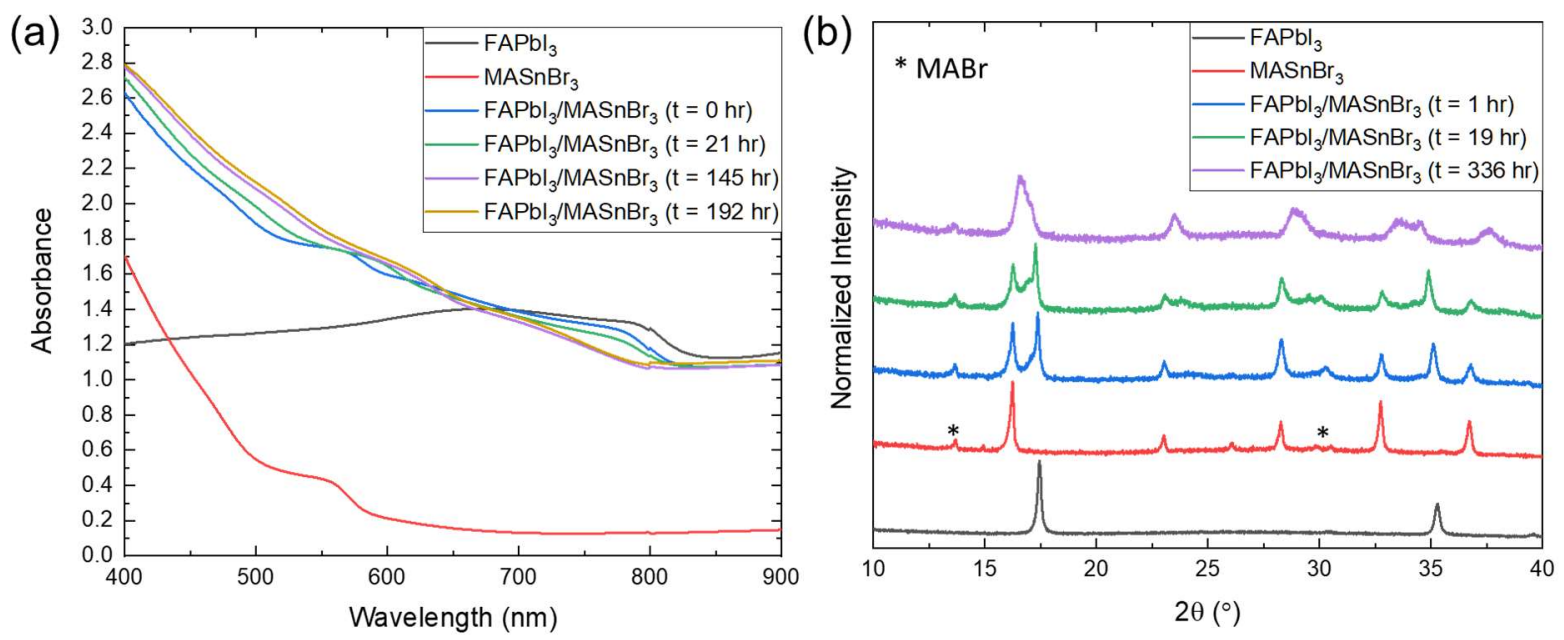

Figure S8. Representative absorbance spectra (a) and XRD patterns (b) of a $\mathrm{FAPbI}_{3} / \mathrm{MASnBr}_{3}$ heterojunction. Absorbance spectra for films containing $\mathrm{FAPbI}_{3}$ have a large background due to scattering from the films; all films appeared dull to the eye. XRD patterns of both $\mathrm{MASnBr}_{3}$ and heterojunctions show a small peak due to excess $\mathrm{MABr}$ at $2 \theta=14^{\circ}$, it is possible that these nonstoichiometries could have contributed to faster mixing via altering the defect distribution. XRD measurements show peaks corresponding to both constituent layers at $\mathrm{t}=0 \mathrm{hr}$, and evidence of substantial mixing at $\mathrm{t}=336 \mathrm{hr}$. XRD was collected using Co $\mathrm{K} \alpha$ radiation and spectra are normalized to maximum and offset for clarity. 

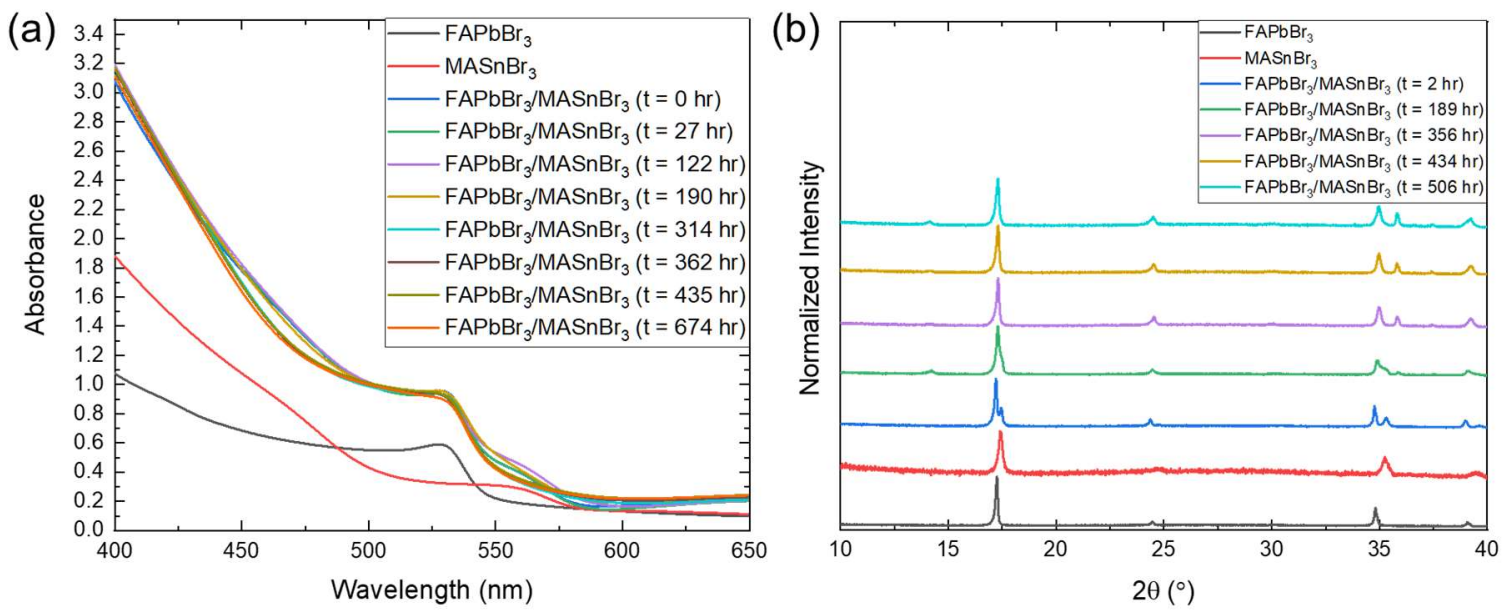

Figure S9. Representative absorbance spectra (a) and XRD patterns (b) of a $\mathrm{FAPbBr} 3 / \mathrm{MASnBr}_{3}$ heterojunction. Initial absorbance spectra $(t=0 \mathrm{hr})$ and XRD peaks $(t=2 \mathrm{hr})$ show features corresponding to both constituent layers. As these films mix, the absorbance spectra eventually evolve to show only one onset feature, visible at $\mathrm{t}=314 \mathrm{hr}$. Similarly, only one set of diffraction peaks corresponding to the alloy is present after $\mathrm{t}=356 \mathrm{hr}$. These times also correspond the times at which the absorbance and XRD patterns stop changing, and are examples of the "mixing times" shown in Figure 2a. XRD was collected using Co Ka radiation and spectra are normalized to maximum and offset for clarity. 


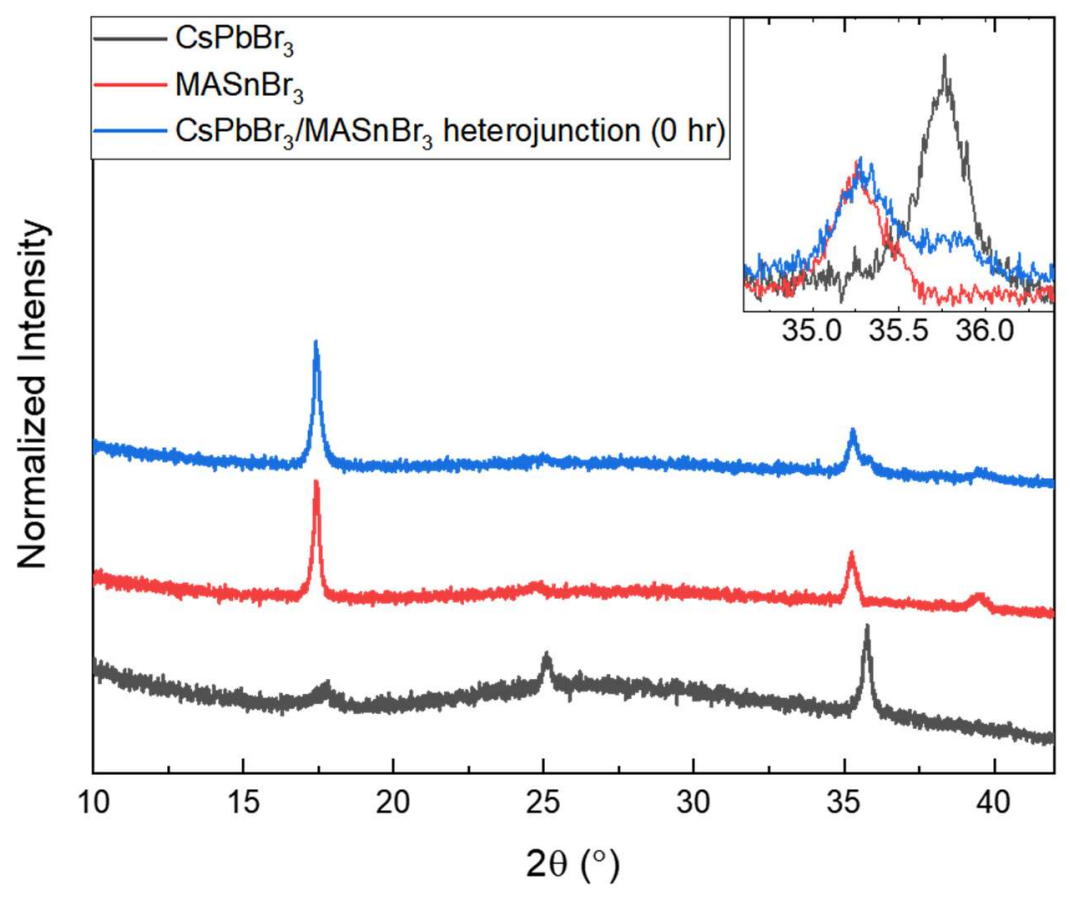

Figure S10. Representative XRD patterns of a $\mathrm{CsPbBr}_{3} / \mathrm{MASnBr}_{3}$ heterojunction. XRD was collected using Co Ka radiation and spectra are normalized to maximum and offset for clarity. 


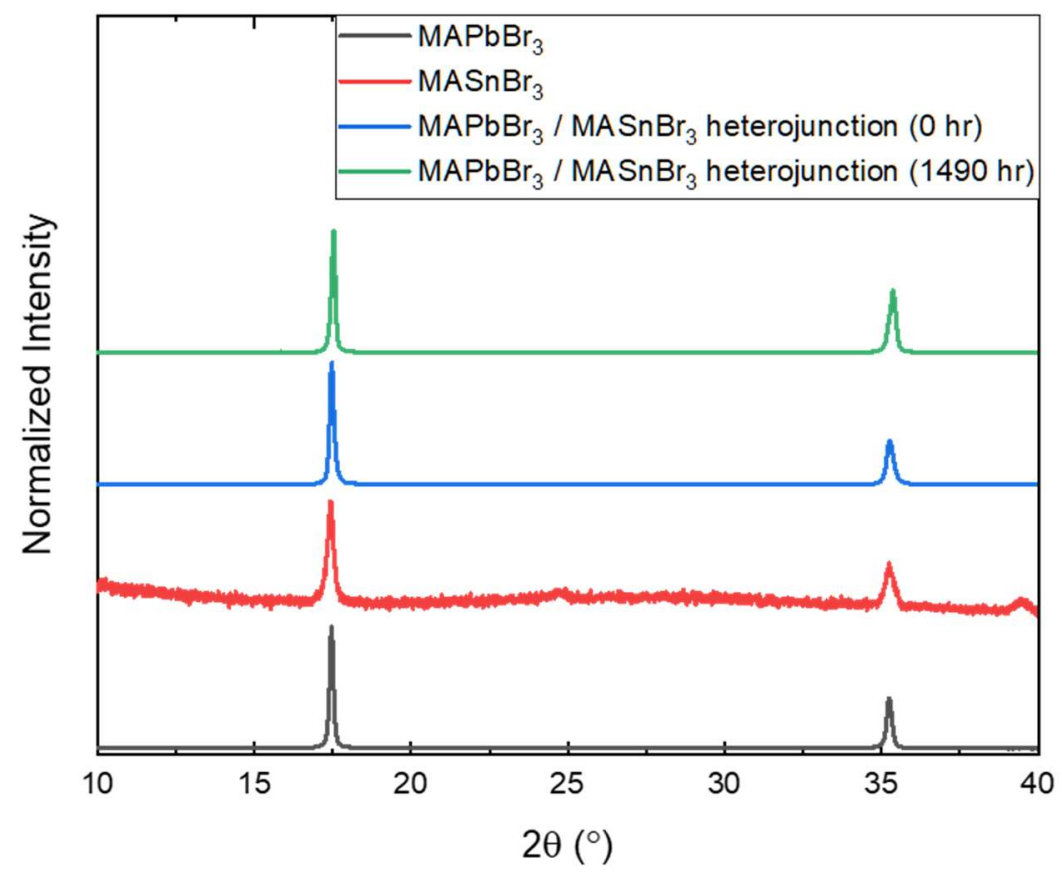

Figure S11. Representative XRD patterns of a $\mathrm{MAPbBr} 3 / \mathrm{MASnBr}_{3}$ heterojunction. XRD was collected using Co Ka radiation and spectra are normalized to maximum and offset for clarity. 


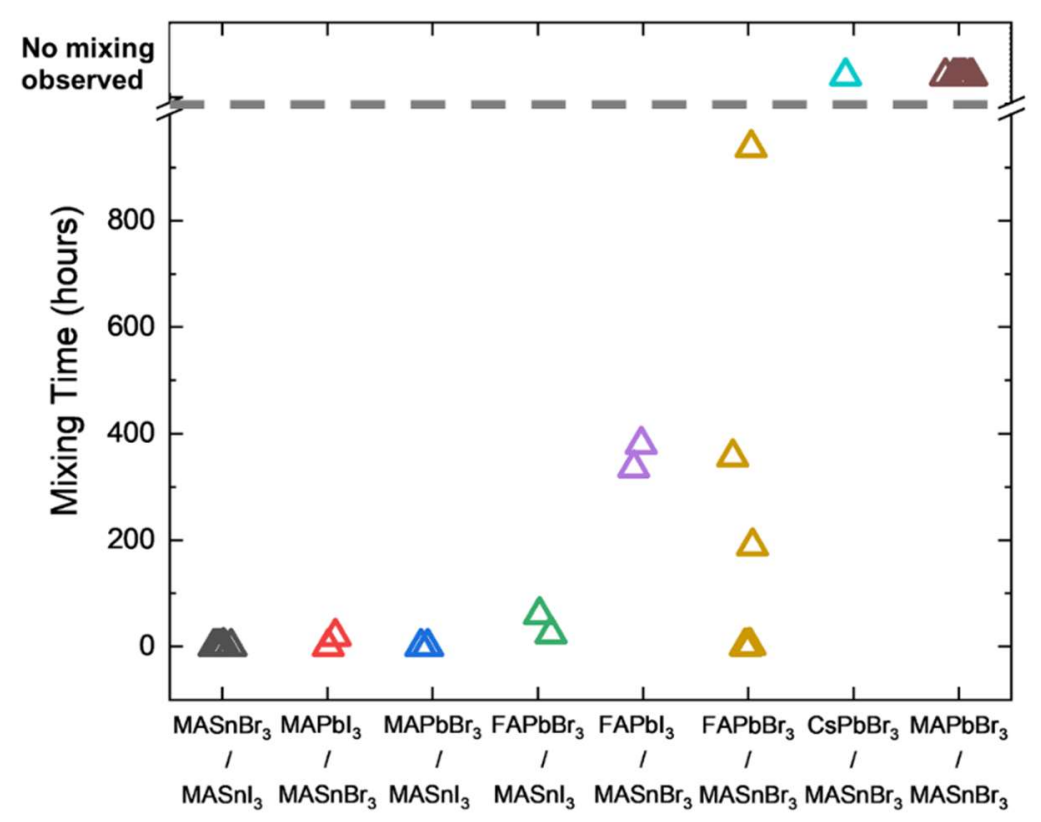

Figure S12. Approximate mixing times for samples used to determine the ranges in mixing times depicted in Figure 2a. Mixing times are assigned based on the time elapsed between fabrication and when absorbance spectra or XRD pattern show a single onset feature or set of diffraction peaks. The resolution for mixing time varies between samples due to different mixing rates but is typically $\sim 24$ hours as a result of daily absorbance and XRD scans. Each triangle corresponds to a single layered structure, and multiple triangles denote different samples. Note that the deposition conditions and resulting morphology of the layers was kept as consistent as possible between samples with the exception of the $\mathrm{FAPbBr}_{3} / \mathrm{MASnBr}_{3}$ and $\mathrm{MAPbBr} 3 \mathrm{MASnBr}_{3}$ heterojunctions, where the bottom $\mathrm{Pb}$ film morphology was intentionally varied as discussed in the main text. Thus in the case of $\mathrm{FAPbBr}_{3} / \mathrm{MASnBr}_{3}$, the variability between samples of the same composition is likely due to differences in morphology. 

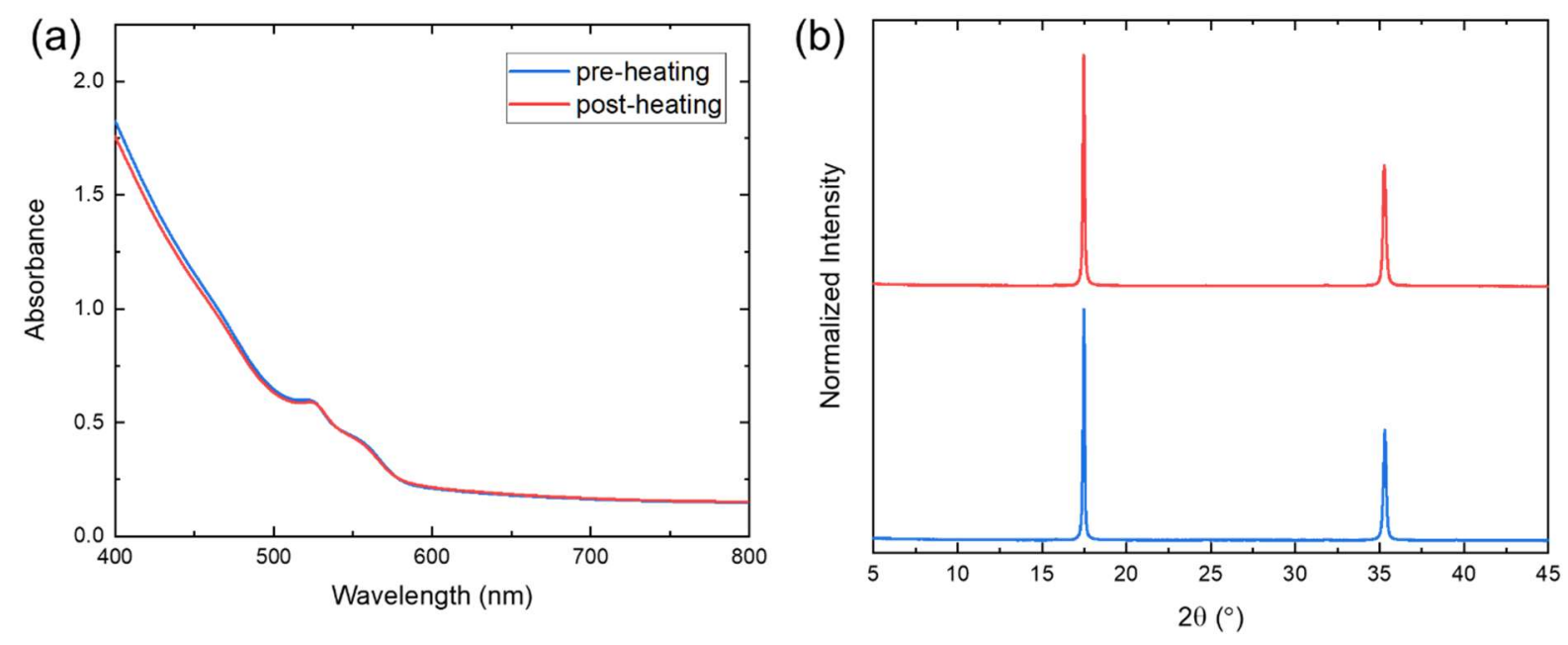

Figure S13. Absorbance spectra (a) and XRD patterns (b) of a $\mathrm{MAPbBr}_{3} / \mathrm{MASnBr}_{3}$ heterojunction before and after heating at $60{ }^{\circ} \mathrm{C}$ for 7 hours in an $\mathrm{N}_{2}$ atmosphere. No appreciable change in XRD pattern or absorption features is observed after heating, indicating a lack of substantial B-site cation diffusion across the interface. XRD was collected using Co $\mathrm{K} \alpha$ radiation and spectra are normalized to maximum and offset for clarity. 

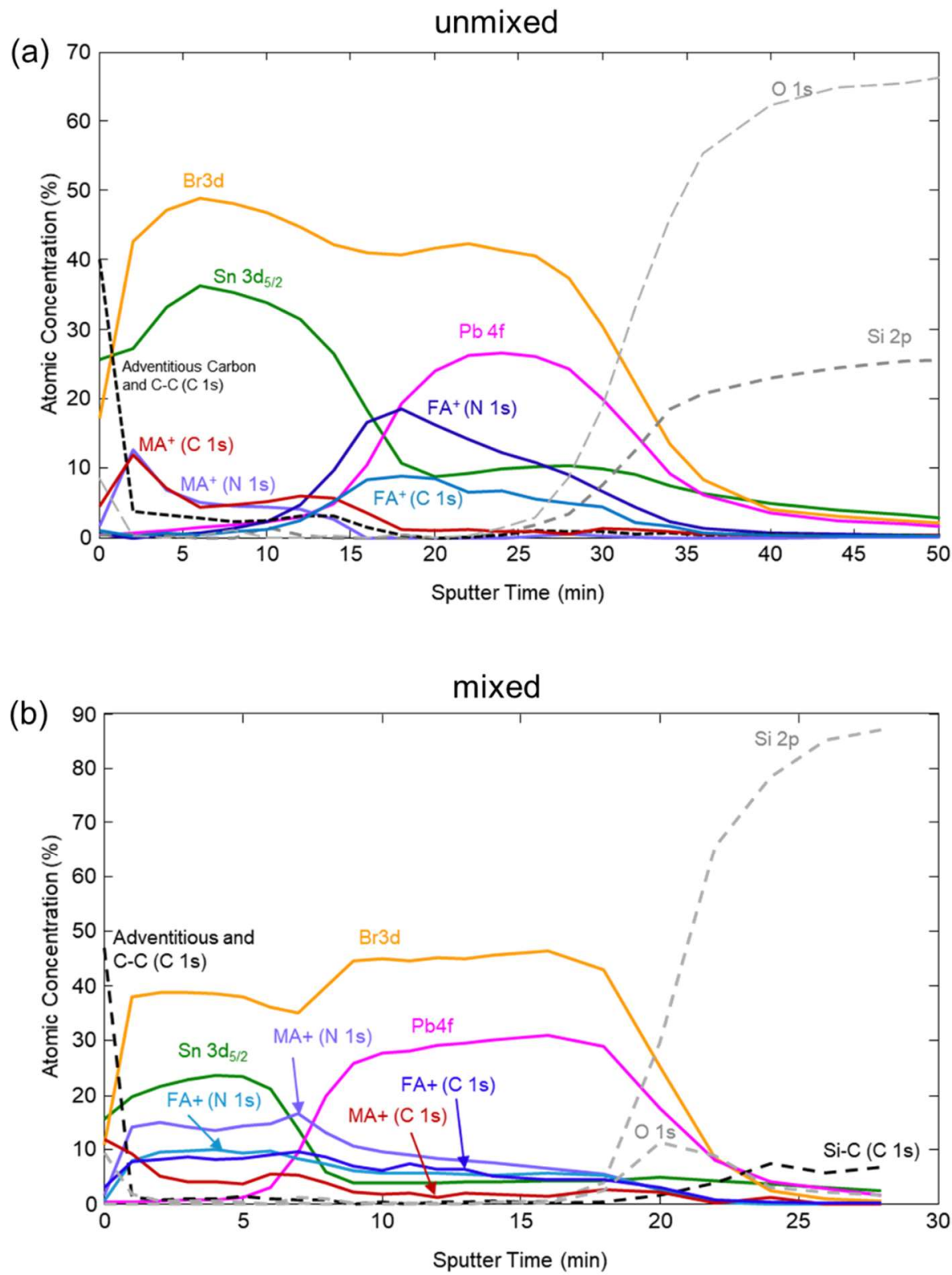

Figure S14. XPS depth profile corresponding to the unmixed (a) and mixed (b) $\mathrm{MASnBr} 3 / \mathrm{FAPbBr}_{3}$ samples in Figures $3 \mathrm{~d}-3 \mathrm{~g}$. The sharpness of the transition from $\mathrm{Sn} 3 \mathrm{~d}_{5 / 2}$ and $\mathrm{Pb} 4 \mathrm{f}$ profiles appears similar for both mixed and unmixed films, indicating minimal diffusion of the $\mathrm{B}$-site $\left(\mathrm{Sn}^{2+}\right.$, and $\left.\mathrm{Pb}^{2+}\right)$. However, the relative intensities of the $\mathrm{C} 1 \mathrm{~s}$ and $\mathrm{N} 1 \mathrm{~s}$ signals corresponding to $\mathrm{MA}^{+}$and $\mathrm{FA}^{+}$species differ dramatically for the un-mixed and mixed cases: the unmixed film transitions from only $\mathrm{MA}^{+}$signal at the top of the film to only $\mathrm{FA}^{+}$signal after $\sim 20$ 
mins of sputtering, but the mixed film has both $\mathrm{MA}^{+}$and $\mathrm{FA}^{+}$signals present throughout. The difference in chemical environment for both carbon and nitrogen in $\mathrm{MA}^{+}$and $\mathrm{FA}^{+}$can be observed with XPS. As a result, the chemical states for each $\mathrm{MA}^{+}$and $\mathrm{FA}^{+}$can be separated and plotted as a function of sputtering time.

(a)

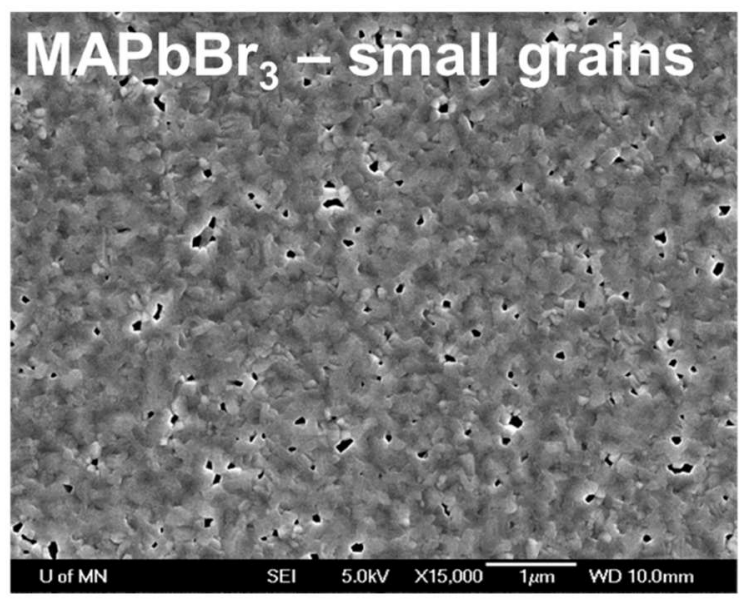

(c)

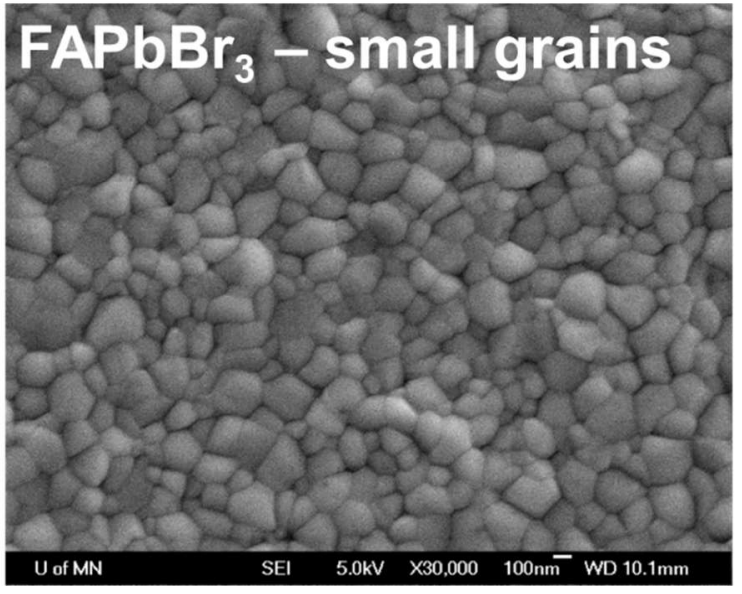

(b) $\mathrm{MAPBBr}_{3} \rightarrow$ large islands

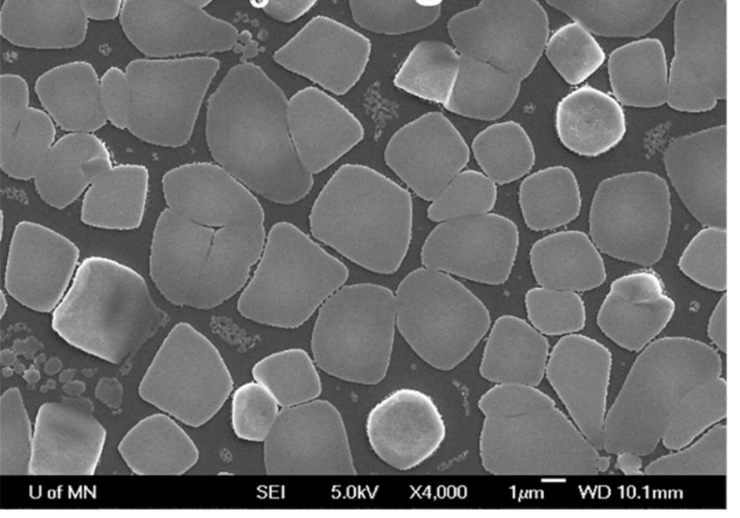

(d)

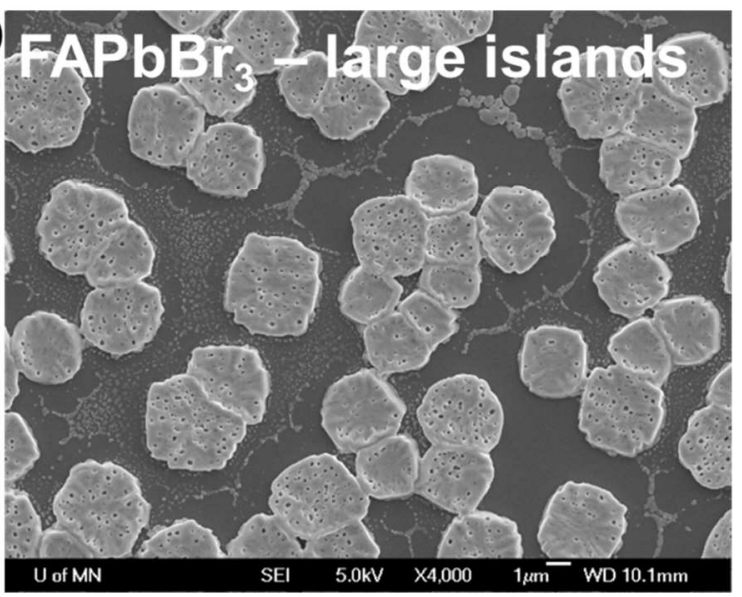

Figure S15. SEM images for small-grained (a) and large-island (b) $\mathrm{MAPbBr}_{3}$ and small-grained

(c) and large-island (d) $\mathrm{FAPbBr}_{3}$. Small-grained and large-island films were fabricated by dripping $200 \mu \mathrm{L}$ chlorobenzene 10s and 40s, respectively, into the spin-coating process. Scalebars are $1 \mu \mathrm{m}$ (a), (b) and (d) and $100 \mathrm{~nm}$ (c). 


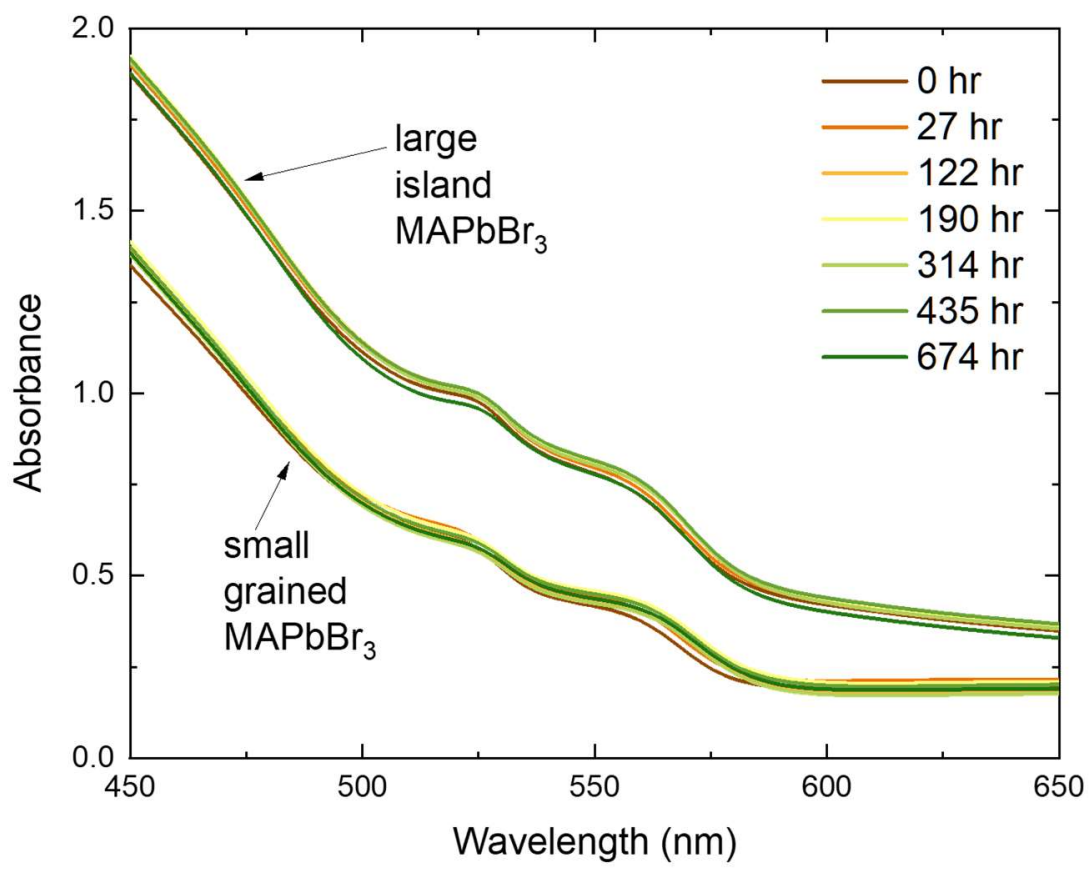

Figure S16. Absorbance spectra of $\mathrm{MAPbBr}_{3} / \mathrm{MASnBr}_{3}$ heterojunctions as a function of grain size and time. All times show distinct absorption features corresponding to both layers and no substantial changes over time, indicating a lack of mixing across the interface. Films were stored at room temperature in an $\mathrm{N}_{2}$ glovebox between measurements. 
(a)

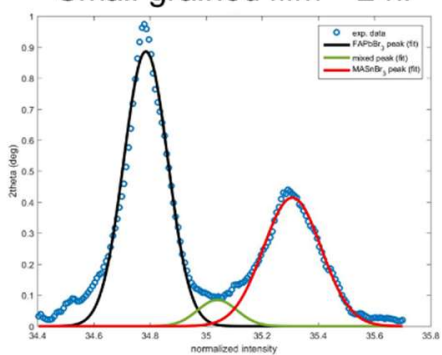

Small grained film $-434 \mathrm{hr}$

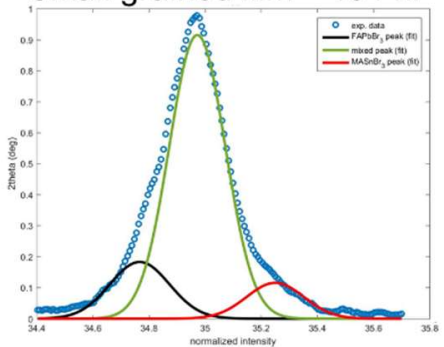

(b)
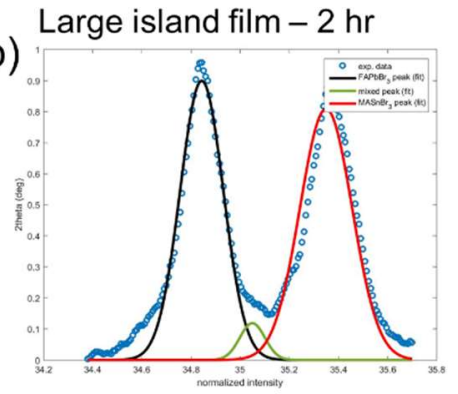

Large island film - $434 \mathrm{hr}$

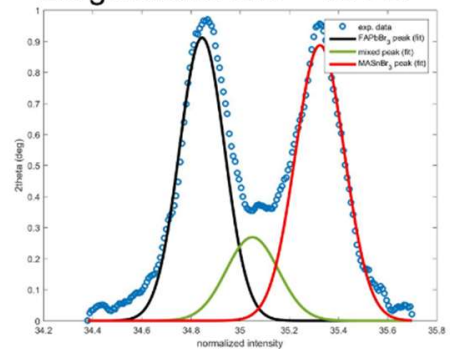

Small grained film - $189 \mathrm{hr}$

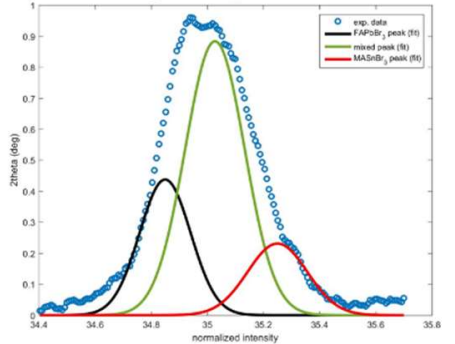

Small grained film $-506 \mathrm{hr}$

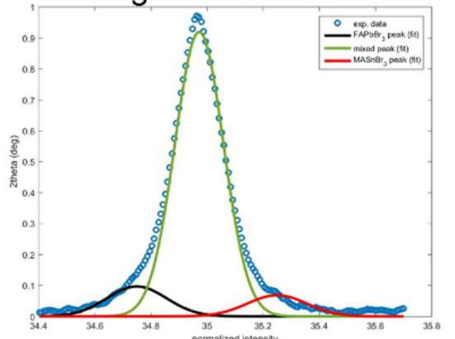

Large island film - $189 \mathrm{hr}$

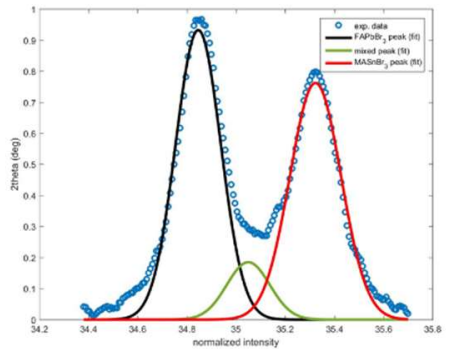

Large island film $-506 \mathrm{hr}$

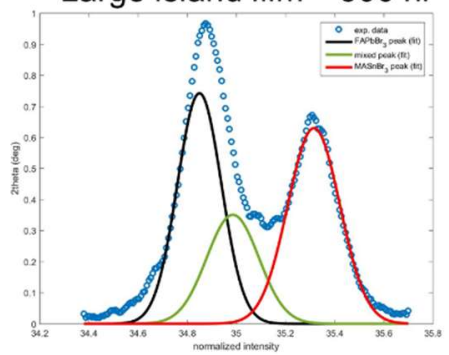

Large island film - $356 \mathrm{hr}$
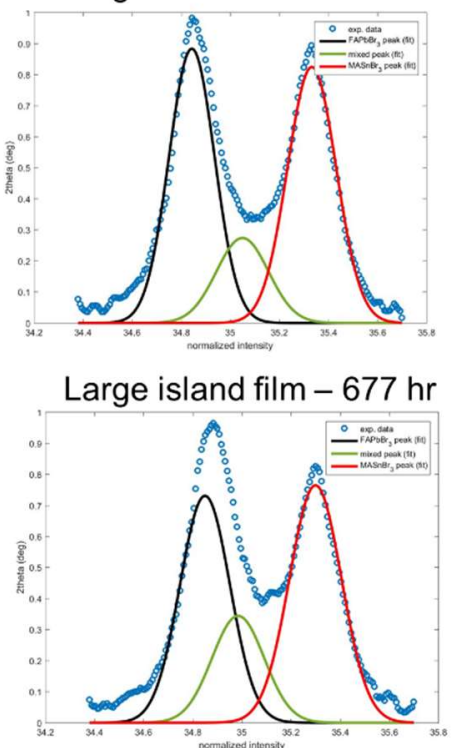

Figure S17. Results of fitting for one small-grained and one large-island $\mathrm{FAPbBr} 3 / \mathrm{MASnBr}_{3}$ heterojunction shown in Figure 4b. XRD was collected using Co Ka radiation and spectra are normalized to maximum and offset for clarity. 


\section{REFERENCES}

(1) Cho, H.; Wolf, C.; Kim, J. S.; Yun, H. J.; Bae, J. S.; Kim, H.; Heo, J.; Ahn, S.; Lee, T. HighEfficiency Solution-Processed Inorganic Metal Halide Perovskite Light-Emitting Diodes. $A d v$. Mater. 2017, 29, 1700579. https://doi.org/10.1002/adma.201700579.

(2) Binek, A.; Hanusch, F. C.; Docampo, P.; Bein, T. Stabilization of the Trigonal High-Temperature Phase of Formamidinium Lead Iodide. J. Phys. Chem. Lett. 2015, 6 (7), 1249-1253. https://doi.org/10.1021/acs.jpclett.5b00380.

(3) Clark, C. P.; Voigt, B.; Aydil, E. S.; Holmes, R. J. Carrier-Gas Assisted Vapor Deposition for Highly Tunable Morphology of Halide Perovskite Thin Films. Sustain. Energy Fuels 2019, 3 (9), 2447-2455. https://doi.org/10.1039/c9se00200f.

(4) Marshall, K. P.; Walton, R. I.; Hatton, R. A. Tin Perovskite/Fullerene Planar Layer Photovoltaics: Improving the Efficiency and Stability of Lead-Free Devices. J. Mater. Chem. A 2015, 3 (21), 11631-11640. https://doi.org/10.1039/c5ta02950c. 